\title{
Use of Mixed Methods in a Study of Residence and Contact Disputes between Divorced and Separated Parents
}

\section{Vanessa May}

Received 25 February 2006; Accepted 29 August 2006

This article discusses a study of residence and contact disputes in court which utilised a mixture of quantitative and qualitative methods in order to gain a multidimensional picture of these disputes. It is argued that in a study such as this, the different datasets are best viewed as complementary, rather than as a means of validating each other. The data from each stage address a different aspect of these court disputes, thus offering a better understanding of the complexity of what goes on at court. I examine the ways in which the mixed methods approach improved the research team's ability to interpret the findings. I conclude that the study has highlighted that because there is not just one view of how well the courts work, a variety of criteria needs to be used in evaluating this: when, for whom, for which problems and on which measures.

\section{Introduction}

This article discusses the use of mixed methods in a study on residence and contact disputes in court. I examine how a combination of quantitative and qualitative methods allowed us to gain an understanding of how well the courts 'work' (Smart, May, Wade, \& Furniss, 2003, 2005). The study was conducted in 2002-2005 and funded by the Department for Constitutional Affairs (formerly the Lord Chancellor's Department).

\footnotetext{
Vanessa May is a Research Fellow at the Morgan Centre for the Study of Relationships and Personal Life, School of Social Sciences, University of Manchester, Manchester M13 9PL. Her work focuses on post-divorce parenting and methodology, and has been published in Sociological Review, Women's Studies International Forum, and Narrative Inquiry. Correspondence to: Vanessa May, The Morgan Centre for the Study of Relationships \& Personal Life, School of Social Sciences, University of Manchester, Manchester M13 9PL, UK. Tel.: +44 0161275 0265; Fax: +440161275 2514; Email: vanessa.may@manchester.ac.uk
} 
The focus was on court disputes over residence and contact between separated and divorced parents in three county courts. The majority of parents who separate or divorce are able to agree over their children's living arrangements without involving the legal system. In approximately $10 \%$ of cases, the parents cannot reach an agreement, and turn to the courts to apply for a residence or contact order (Blackwell \& Dawe, 2003). The meaning of a 'residence order' is defined in Sec. 8(1) of the Children Act 1989 as 'an order settling the arrangements to be made as to the person with whom a child is to live'. The same section defines a 'contact order' as

an order requiring the person with whom a child lives, or is to live, to allow the child to visit or stay with the person named in the order, or for that person and the child otherwise to have contact with each other.

Our study aimed to examine three aspects of residence and contact disputes in court: first, why parents brought their cases to court and what their expectations were; second, how the courts dealt with these disputes; and third, what impact going to court has on such families, especially in the longer term. We wanted to understand these effects against the background of the kinds of issues that parents brought to court and how the courts dealt with these cases. In order to answer these questions it was necessary to collect data both on the court process and from parents themselves.

The study was divided into four stages, each stage examining a different angle of and addressing different questions relating to the phenomenon 'residence and contact disputes in court' and requiring the employment of different methods of data collection. The first stage consisted of a statistical overview of court cases in order to gain an understanding of the types of issue brought to court and how these were dealt with. The second stage comprised case studies of a smaller sub-sample of court files that provided insight into the mechanics of particular types of case. In the third stage, we conducted a postal survey of parents' views of the courts for a broad understanding of both the negative and positive aspects that going to court held for them. In the fourth stage, we carried out qualitative semi-structured interviews with 61 parents who had been to court over residence and contact in order to gain an indepth understanding of the complex and dynamic issues involved for these families. In this article, I discuss why we decided to employ more than one method; how we went about combining four methods (and which methods were more successful than others and why); and our choice of publication output. In the final section of this article, I evaluate what we gained (and lost) by using a mixed methods approach. As usually tends to be the case in accounts detailing research methods, the narrative I provide below gives the picture of a smoother process than it in actual fact was.

\section{The Case For Mixed Methods}

There is a long-standing and well-rehearsed debate over whether it is viable to combine qualitative and quantitative methods in one study (cf. Bryman, 1988, 2004; Hammersley, 1992; for an overview of this debate). Those against mixing methods 
argue that qualitative and quantitative methods are based on different epistemological and ontological commitments that prevent efforts to combine them in a meaningful way. The argument for combining methods is based on the pragmatic view that there are considerable similarities between qualitative and quantitative methods-for example, the use of observations and the creation of interpretative narrative conclusions on the basis of findings - and that the connections between epistemology/ontology and research method are tendencies rather than definitive connections (Brannen, 2005; Bryman, 2004; Onwuegbuzie \& Leech, 2005). Furthermore, the selection of a method ought to depend on the purposes and circumstances of the research, rather than being derived from methodological and philosophical commitments (Hammersley, 1992). Hence, this article argues for collecting and combining qualitative and quantitative data in the same study where this is called for by the research questions and where it is practicable to do so.

It is important to keep in mind that the relationship between epistemology/ontology and research method works the other way round as well, in that our ways of seeing and framing questions are strongly influenced by the methods we use (Mason, 2006). Thus, adhering to only one method can lead to conservatism of thought, of repeatedly asking the same questions while failing to pose innovative questions that would illuminate the social world in a new way.

An often used argument for employing more than one method is that this offers the chance for 'triangulation' (cf. Fielding \& Schreier, 2001; Kelle, 2001 for an overview). Traditional notions of triangulation are based on the notion of 'objective' data that examine the same research problem and unproblematically reflect the 'real' world, and that therefore can be piled up in an additive way in order to increase the internal validity' of a study's findings.

The choice of a mixed methods approach in this study is based on a different view on the nature of 'reality' and knowledge. Data are not 'objective' but rather constituted by the method that generates them. Consequently, data can only be understood in relation to the purposes for which they are created and different datasets do not add up to some rounded unity. Different methods are complementary, that is, they construct different objects, and represent different perspectives or levels of 'reality' (Mason, 2006). This article therefore proposes that the findings from the different elements of a mixed method study are best combined like pieces of a jigsaw puzzle with the aim of gaining a more complex understanding of the social world, rather than as a means of validating each other.

Consequently, we analysed the different datasets independently of each other in relation to the different research questions that helped generate them (cf. Brannen, 2005). Differences between datasets are likely to be as illuminating as their similarities and do not automatically represent proof that the findings of one method are 'false' or erroneous, but rather can act as a springboard towards finding an alternative theoretical framework that would integrate these findings (Hammond, 2005). As a consequence, mixing methods can at best provide the key to innovative ways of understanding a phenomenon by offering new ways of 'connecting the dots' and creating something above and beyond the two separate datasets. 
In other words, mixing methods can offer potential for exploring new dimensions and for asking new questions (Hammond, 2005). Because social phenomena are multifaceted, they require a variety of approaches in order to be studied in a way that conveys their complex nature (Mason, 2006). A court case is a meeting point for different institutions and actors (e.g. parents, children, solicitors, judges and CAFCASS officers) whose actions are based on partly differing principles (James, 2003; Smart \& May, 2004). Thus legislation, legal practice and 'lay' experience interact in a complex manner. Previous research has provided an understanding of the role that representatives of different parts of the legal system — such as lawyers, judges and CAFCASS officers-play in residence and contact disputes (e.g. Davis \& Pearce, 1999; Eekelaar, MacLean, \& Beinart, 2000; James \& Hay, 1993). The aim of our study was to gain a more holistic picture of how the legal system operates in these cases. In addition, we wanted to compare this with how the parents perceived the process and what effect they believed it had on their family life.

Thus, our study addressed different dimensions of residence and contact disputes in court. Layder (1993, p. 8) has devised what he calls 'the research map', where he sets out the different levels that research can address: context with a research focus on macro social forms; setting, that is, the immediate environment of social activity; situated activity or the dynamics of face-to-face interaction; and the self in the form of biographical experience. These four levels are interlinked; although each exists 'on its own' and can be researched separately, they are nonetheless linked and simultaneous. It is not my intention in this article to go into the discussion as to whether there exist 'objective' social structures outside of human action, and what the precise relationship between 'structure' and 'agency' is - whether the whole is a sum of its parts or whether collective phenomena have emergent properties that are irreducible to the actions of individuals (e.g. Archer, 1995; King, 1999; Bates, 2006; Sawyer, 2001). For the purposes of this article, it is enough to note that society can be studied with the help of concepts such as 'macro' and 'micro', and that macro structures shape micro interactions and micro interactions in their turn shape structures (Archer, 2000). Furthermore, both act jointly at the same time and thus they do not exist independently of each other; for example, structures are relational and would therefore not exist without interaction (Archer, 2000; Bates, 2006). Returning to Layder's research map, the four levels in our study were: legislation and policy guidance (Context); the courts (Setting); the court process (Situated activity); and the dispute and the court process as experienced by the parents (Self). A multimethod approach can attend to the links between these different levels of social life, without undervaluing or overstressing any one of them. Thus, multistrategy research is not the same as 'anything goes' eclecticism, but rather entails finding the appropriate tools to investigate specific research questions. As the discussion below illustrates, however, it is not only the research question that should guide the choice of method, as in some instances a particular method may simply be 'wrong' or unworkable. We found this to be the case when trying to conduct a survey with a courtbased sample of parents whose contact with the courts had occurred a few years prior to the research. In the following section, I examine more closely the questions we were seeking to ask and the methods we devised for asking them. 


\section{How We Mixed Methods}

The aim of our study was to gain a holistic understanding of the court process and the impact that going to court over residence and contact has on the lives of families. This meant that we needed to both understand what goes on at court and what this process meant to the parents involved. Because we wanted to find out what effect a court dispute had on family relationships over time, we decided to sample cases that had begun two years before our study commenced. Below, I discuss each of the four stages of our research, the findings of which are summarised in two reports (Smart et al., 2003, 2005):

- Stage 1: An overview of court cases

- Stage 2: Understanding the court process

- Stage 3: Questionnaire survey of parents

- Stage 4: In-depth interviews with parents

\section{Stage 1: An Overview of Court Cases}

Stage 1 of our study consisted of a quantitative overview of residence and contact disputes brought to the three county courts in the year $2000(n=430)$. We chose a random sample of case files from that year and collected data on the main characteristics of these cases, such as the grounds on which the parties brought their cases to court; the age and marital status of the parents; the ordering of CAFCASS or Social Services reports; whether the children's views had been sought; the time taken from application to issuing a court order or withdrawal of the case; and the types of order granted. The data were entered into and analysed with the help of SPSS.

The findings from Stage 1 show that contrary to the commonly held view that the majority of applications brought to court are to do with contact, $60 \%$ of the cases fell under our definition of a residence case. Unsurprisingly, mothers tend to make applications for residence, while fathers mainly apply for contact orders. But we also found an unexpectedly large number of grandparents making residence and contact applications. The fear that a non-residential father would remove the children seemed to be of particular concern to the residential mothers who applied for residence. For fathers, the main reasons for applying for contact were that contact was not working satisfactorily or was being refused completely by the mother. Roughly, a quarter of cases included allegations of domestic violence.

In terms of the efficiency of the courts, the majority of residence cases were concluded in six months, while contact cases were on average lengthier, with the majority of cases concluded only after nine months. The 'success' rate of both residence and contact applications was the same, with $44 \%$ and $46 \%$ of applicants, respectively, receiving the order they had applied for. Only a small minority of contact cases ended with the applicant being granted only indirect contact or with contact being denied completely. We did not find major differences in the types of case or in the handling of cases between the three courts. 


\section{Stage 2: Understanding the Court Process}

In Stage 2, we conducted a case study analysis of 180 court files. This theoretical sample was derived from the original sample of 430 cases to address issues that had arisen from the analysis of the data from Stage 1. The types of case we wished to explore further were: protracted cases; cases involving allegations of domestic violence; cases where children had been consulted; cases that included orders for restricted or no contact; and cases involving applications from grandparents. We wrote comprehensive notes on the basis of the information included on file and created case synopses. Each synopsis was then entered as documents into NVIVO to aid comparison and analysis. The aim in Stage 2 was to analyse the process of these cases in more detail, including a detailed reading of all statements and reports on file. In NVIVO, each document or case was coded under central themes such as 'domestic violence' or 'protracted dispute', but apart from that, the documents were analysed holistically. This means that rather than collecting together coded bits of text as is usually done in NVIVO, we grouped whole documents together on the basis of their central characteristics in order to understand some of the processes that were taking place in cases of similar type. This analysis gave us a picture of how the various involved parties framed the dispute, and how the courts and other affiliated professionals responded to the presenting issues.

The findings from Stage 2 complicated the picture derived from the Stage 1 data. We found that the neat categories we had constructed in Stage 1 hid behind them complex issues and processes. Parents who bring a residence or contact dispute to court are meant to only focus on issues directly related to the welfare and best interests of their children. Issues such as past infidelities and the payment of child support are deemed to be outside the court's focus of attention. However, we found that behind the 'legally approved' issues to do with children's welfare, parents were in dispute over a variety of issues not actually viewed as 'legitimate' by the courts when it comes to deciding over residence and contact issues. The fact that parents are nevertheless keen to flag up such issues we interpreted as an indication that the legal system operates on a different set of moral and ethical principles than the parents do. This was one of the issues we wished to explore further in our in-depth interviews.

\section{Stages 3 and 4: Questionnaire Survey and In-Depth Interviews with Parents}

Because the samples for Stages 3 and 4 were recruited together, I discuss these two stages, particularly the issue of sampling and its consequences, together. Stage 3 comprised a survey we designed for the parents, and Stage 4 consisted of in-depth interviews with parents. For confidentiality reasons, the questionnaire and the invitation to be interviewed had to be sent on our behalf by the courts. These were accompanied with covering letters from the court and from us, stating that the study was independent from the courts, and that participation was voluntary and would in no way affect any future court decisions. Furthermore, it was pointed out that the courts would not have access to the data derived from the questionnaire or the interviews. 
The response rate for the survey was extremely low, with only $9 \%$ of the questionnaires returned $(n=112)$. The low response rate can probably partly be explained by the fact that a large number of questionnaires not reaching the recipients; the courts estimated that approximately one fifth of the questionnaires were returned because the addressee had moved. Furthermore, it is probable that many recipients declined to take part in our study because it focused on a distressing or painful personal issue that they wished not to delve into. The parents we did speak to indicated that receiving a letter from court had caused some initial sense of dread that the dispute had been taken back to court by the other parent, while other parents left us phone messages informing us that they had felt our letter to be intrusive and had been upset by receiving it. This leads me to conclude that in court-based samples, especially ones going back some years, the survey method is perhaps unsuitable for all the reasons stated above.

In Stage 4, we conducted qualitative semi-structured interviews with parents involved in these disputes ( $n=61 ; 34$ mothers, 27 fathers) - most of these had also filled in the questionnaire. Originally, we had intended to recruit the interview sample from the cases we had analysed in the first two stages of this study, especially Stage 2, but this turned out to be unfeasible because we were unable to contact the parents directly and were reliant on those parents who volunteered to be interviewed in response to our letter and questionnaire. Thus, our interview sample consists of parents who had a special interest in taking part in our study, not least giving voice to their disappointment with the court process. This probably partly explains why the interview sample consisted of parents whose court disputes were from the more conflictual end of the scale.

Because of the low response rate, the findings from our survey are not statistically representative, and we have utilised them only sparingly. However, we felt that we could draw on the data to some extent because the data from the first two stages provided us with an indication of which parents returned the survey questionnaire and agreed to be interviewed: contact disputes and cases involving a high degree of conflict were overrepresented. Over $71 \%$ of the questionnaire respondents had been involved in a contact dispute (against $40 \%$ in our sample of cases in Stage 1), while $68 \%$ of the interviewees said their cases had involved a CAFCASS/Social Services report (compared to $47 \%$ in Stage 1). Both of these factors indicate a higher than average level of conflict. Therefore, we have stressed that any results from the survey or the interviews cannot be generalised to all residence and contact disputes. Rather, they are indicative of what the issues are for parents who are involved in the lengthier and more complex contact cases.

The findings from the survey indicated that contact parents $(n=58)$ - who tended to be fathers-were far more dissatisfied with the courts than residential parents $(n=$ 47 ; the rest were parents with shared residence)-mainly mothers-were. Of the contact parents, only $21 \%$ believed the outcome of their case was the right one, as opposed to $55 \%$ of residential parents. Similarly, $43 \%$ of contact parents but only $26 \%$ of residential parents believed that the court case had made things worse or much worse. Only $19 \%$ of contact parents but $36 \%$ of the residential parents agreed that the courts are a suitable place to solve such conflicts. The findings from the questionnaire 
therefore indicate that parents who have been involved in a contact dispute and who have experienced a relatively high level of conflict are relatively dissatisfied with how the courts work, and that fathers generally tend to be more dissatisfied than mothers are. These were issues we wanted further to explore in our in-depth interviews. Is it so that mothers have little to criticise about their experiences of the court system?

The interviews were loosely structured because we wanted to capture the parents' own views and experiences. The interviews lasted on average 45 minutes to one hour and were conducted mainly at home with the parents. Although we had devised an interview schedule in advance to aid the interviewers, each interview narrative focused on a slightly different array of issues because every court dispute is different. Furthermore, the interview participants tended to have plenty to say about their experiences, thus rendering the interviews more like conversations than question and answer sessions.

We opened each interview by stating that we were interested in hearing about what had led to the dispute being taken to court, what had happened at court and during the court process, and what the parents thought of these events. We also indicated that we were equally interested in hearing about developments around the issue of arrangements for children after the court case had concluded, as well as about the effect that going to court had had on the dispute and on family relationships. The interview tapes were transcribed and the transcriptions were analysed with the help of NVIVO. We conducted both case study analyses and thematic analyses across cases.

Although we were not looking for corroborating evidence, it was interesting to note the similarities between the interview data and the findings from earlier stages of the research (cf. Brannen, 2005, p. 180). The findings from Stage 2 relating to the complexity of the disputes were supported and expanded in the interviews. The parents did indeed indicate that they had gone to court with a multitude of grievances that they hoped the courts would adjudicate. Instead, they found that the courts were not interested in hearing about the parents' past relationship or issues to do with paying child support. What the data from the court files could not convey but came through clearly in the interview data was the strength of feeling among parents around these concerns. We concluded that these issues, though 'illegitimate' in the eyes of the law and often viewed as 'selfish' because not focusing on the children's welfare, were for the parents themselves moral and ethical matters that they could not simply overlook, though encouraged to do so by the legal system (May \& Smart, forthcoming).

We also found that contrary to the questionnaire findings, when constructing a narrative of their experiences rather than ticking boxes for pre-determined answers, the mothers did not appear to be more satisfied with the courts than fathers were. This 'discrepancy' in findings could perhaps be interpreted as a result of women's reluctance to be negative or critical when responding to direct survey questions (cf. Brannen, 2005 , p. 179), or as simply the result of us not asking the 'right' questions in the questionnaire (cf. Popay et al., 2003 on apparent discrepancies between survey and interview responses, which they believed to be partly the result of the questions asked). Whereas the fathers were highly critical of the system, and it was indeed the legal system and its various representatives that the questionnaire focused on, the mothers appeared 
more critical of the process they had been through. Mothers seemed to have slightly more diffuse objects of criticism that our questionnaire was not designed to capture.

Furthermore, we found in the interviews that many of the parents were engaged in a parenting contest: they presented themselves as the 'good' caring parent, while their former spouse was relegated to the role of the 'bad' parent who was unable or unwilling to ensure the children's well-being. This, coupled with their deeply held ethical beliefs, meant that for many parents, 'giving up the fight' or backing down from their arguments in the case was inconceivable (May \& Smart, forthcoming). They had constructed their arguments as representing their children's best interests - and had invested their own identity as a 'good' parent in the dispute. Consequently, conceding 'defeat' and agreeing with an outcome different to that they had hoped for, would have meant either concurring that their evaluation of what constituted their children's best interests had been mistaken or colluding with an outcome that they did not believe represented their children's best interests. Calls for parents who find themselves in this situation to simply focus on their children's welfare therefore have little chance of having the desired effect of reducing conflict because these parents would argue that that was exactly what they were doing and that their children's best interests demanded that they not give up the fight.

\section{Publication Strategies}

One important question that needs to be considered when conducting mixed method research is that of how the findings are to be presented. Should the findings from the different elements of the study appear in the same publication or should they be published separately? We published the main bulk of our findings in two separate reports. Volume 1 (Smart et al., 2003) contained the findings from Stages 1 and 2, whereas the findings from Stages 3 and 4 were published in Volume 2 (Smart et al., 2005). This decision was largely driven by our wish to get our findings into the public domain as soon as possible. The rules of embargo set by the funder, the Department for Constitutional Affairs, stated that we were not allowed to present, discuss or publish any findings before they had been officially published in a report. This meant that we had to choose between publishing our findings piecemeal or waiting until the end of the project before sharing our findings with the academic, legal and lay public. We decided to expedite this process by publishing our findings from the court files midway through the project.

Our strategy of giving out two separate publications probably affected our analysis and writing. The data collection for Stages 1 and 2 took place within months, and the data from these two stages were to a large degree analysed concurrently. This meant that the findings from the first two stages are well integrated. The data for the third and fourth stages were collected after we had finished writing Volume 1 of our report. Although the questionnaire design and the focus of the interviews were guided by the findings from the first two stages, this has perhaps remained implicit in the write-up of our findings. In addition, the questionnaire and interview data were not able to feed into our analysis of the court files, while our analysis of the questionnaire and interview 
data could have been more in dialogue with the findings from the first two stages. As a result, the two reports have ended up being relatively freestanding publications.

\section{What Did We Gain by Combining Methods?}

As discussed above, our multi-method strategy was driven by our aim of gaining a holistic understanding of residence and contact disputes in court: that is, the legal process and parents' experiences. Our combination of methods did enable us to reach some important conclusions about the nature of these disputes. Already the data from the court files highlighted the fact that many parents bring to court issues and disputes that by law are considered 'irrelevant', such as disputes over money or past behaviour as a spouse. This finding was corroborated by the subsequent interview data. The interview data also supported our hypothesis that this apparent difference in perspective led to parents feeling a deep level of dissatisfaction with the courts, because they believed that the court had reached its decision on the basis of erroneous or irrelevant facts. One consequence of this mismatch between the legal system on the one hand and lay expectation and experience on the other was that many of the parents we interviewed expressed bafflement over the court's decision and understandably were reluctant to accept it as just.

Because the four elements of the study focused on different aspects of residence and contact disputes, our aim was not to compare the datasets in order to increase the validity of our findings. The different datasets represent different pieces of the jigsaw puzzle that is 'residence and contact disputes in court'. However, we did come across some interesting differences between the datasets, for example, the difference in satisfaction levels between the questionnaire and interview samples, as discussed above. We concluded that this disparity was probably produced by the different methods: that is, that women are perhaps less likely to be critical when answering direct questions than they are in interviews. In addition, our questionnaire was probably not designed to ask the 'right' questions that would have captured mothers' dissatisfaction with the courts, which was more directed at the process rather than particular outcomes or structural organizational factors. Our measures for satisfaction would have needed to be more complex to capture this nuance (cf. Hammond, 2005, p. 248).

Our use of mixed methods also acts as a warning against reading statistical data as simple reflections of any 'reality'. Although the data collected in Stage 1 seemed clearcut but Stage 2 showed that the court cases were not as straight-forward as they appeared but rather involved a multitude of issues. Stages 3 and 4 complicated this picture even further, providing insight into how long-standing many of these conflicts are, and how embedded they are in family history and in issues of identity.

It should however be noted that a research strategy that combines qualitative and quantitative data collection methods is not automatically superior. Any study should be carefully designed so that each element is appropriate to the research problem at hand. Furthermore, the presence of different methodological approaches must be more than cosmetic-more is not always better and one approach must enhance the other. The use of more than one method may also dilute the limited resources 
available. The earlier stages of a mixed methods study can 'blind' one or restrict one's focus in the subsequent elements. For example, in the first two stages of our study, we could not examine class differences because the court files did not contain any such information on the parties to the case. Class in a sense 'dropped off our research agenda and was not picked up in the later stages. We did not gather enough background information on the questionnaires in order to be able to define the respondents' class and neither did we focus on this aspect in the analysis of the interview data.

I conclude that although combining four methods in one study has been time consuming, it has also been fruitful. The data from each stage address a different aspect of the issue of residence and contact disputes in court, thus offering a better understanding of the complexity of what goes on at court. There is not just one view of how the courts work, but rather there exist different criteria for evaluating this. For example, the data from the first stages indicated that the courts were working relatively well, in that they processed the majority of cases within a maximum of six to nine months. But this optimism was nevertheless not entirely borne out by the survey and interview data, which offered a different angle on the issue. Parents themselves do not evaluate the courts on bureaucratic terms but on terms related to their everyday lives. To them, the success of a case was to be evaluated on moral and ethical grounds (e.g. non-payment of child support or leaving a marriage), and we found that the legal system tends to operate to an ethical code that seems alien to many parents.

Furthermore, our study serves as an important reminder to those engaged in conducting small-scale interview studies over how important it is to be able to identify which section of the population one has gained access to (cf. Hammond, 2005, pp. 248-249). For example, had we collected only interview data, we would have come to the conclusion that the courts do not seem to work because of the high degree of dissatisfaction among the parents we interviewed. But as already discussed, the findings from the first stages of the study gave a slightly different picture-from a legal and bureaucratic point of view the courts work relatively well. In addition, the data from the first stages allowed us to identify that the interview participants were mainly parents who had been engaged in disputes on the 'difficult' end of scale with high levels of conflict. This allowed us to temper our conclusions. But on the other hand, had we only collected data from the court files, we would have come away with too optimistic a picture of how well the courts work, having failed to take into consideration the meaning that these processes had in the lives of the parents. Our claim has not been to have found 'the Truth' about the courts, but rather to have gained a clearer understanding of the complexity involved in trying to gauge to what extent the courts 'work'. This question has to be qualified with the further questions of when, for whom, for which problems and on which criteria.

\section{References}

Archer, M. S. (1995). Realist social theory: The morphogenetic approach. Cambridge: University of Cambridge Press. 
Archer, M. S. (2000). For structure: Its reality, property and powers: A reply to Anthony King. Sociological Review, 48, 464-472.

Bates, S. R. (2006). Making time for change: On temporal conceptualizations within (critical realist) approaches to the relationship between structure and agency. Sociology, 40, 143-161.

Blackwell, A., \& Dawe, F. (2003). Non-resident parental contact-based on data from the National Statistics Omnibus Survey for the Department for Constitutional Affairs. London: ONS.

Brannen, J. (2005). Mixing methods: The entry of qualitative and quantitative approaches into the research process. International Journal of Social Research Methodology, 8, 173-184.

Bryman, A. (1988). Quantity and quality in social research. London: Routledge.

Bryman, A. (2004). Social research methods (2nd ed.). Oxford: Oxford University Press.

Davis, G., \& Pearce, J. (1999). A view from the trenches-practice and procedure in section 8 applications. Family Law, 29, 457-466.

Eekelaar, J., MacLean, M., \& Beinart, S. (2000). Family lawyers: The divorce work of solicitors. Oxford: Hart Publishing.

Fielding, N., \& Schreier, M. (2001). Introduction: On the compatibility between qualitative and quantitative research methods. Forum Qualitative Sozialforschung/Forum Qualitative Social Research, 2(1). Retrieved February 1, 2006, from http://www.qualitative-research.net/fqs-texte/ 1-01/1-01hrsg-e.pdf

Hammersley, M. (1992). Deconstructing the qualitative-quantitative divide. In Brannen, J. (Ed.), Mixing methods: Qualitative and quantitative research (pp. 39-53). Aldershot: Ashgate.

Hammond, C. (2005). The wider benefits of adult learning: An illustration of the advantages of multi-method research. International Journal of Social Research Methodology, 8, 239-255.

James, A. (2003). Squaring the circle-the social, legal and welfare organisation of contact. In Bainham, A., Lindley, B., Richards, M., \& Trinder, L. (Eds.), Children and their families: Contact, rights and welfare (pp. 133-156). Oxford: Hart Publishing.

James, A. L., \& Hay, W. (1993). Court welfare in action: Practice and theory. London: Harvester Wheatsheaf.

Kelle, U. (2001). Sociological explanations between micro and macro and the integration of qualitative and quantitative methods. Forum Qualitative Sozialforschung/Forum Qualitative Social Research, 2(1). Retrieved February 1, 2006, from http://www.qualitative-research.net/fqs-texte/ 1-01/1-01kelle-e.pdf

King, A. (1999). Against structure: A critique of morphogenetic social theory. Sociological Review, 47, 199-227.

Layder, D. (1993). New strategies in social research. Cambridge: Polity Press.

Mason, J. (2006). Mixing methods in a qualitatively-driven way. Qualitative Research, 6, 9-25.

May, V., \& Smart, C. (forthcoming). The parenting contest: Problems of ongoing conflict over children. In Maclean, M. (ed) Parenting After Partnering. Oxford: Hart Publishing.

Onwuegbuzie, A. J., \& Leech, N. L. (2005). On becoming a pragmatic researcher: The importance of combining quantitative and qualitative research methodologies. International Journal of Social Research Methodology, 8, 375-387.

Popay, J., Bennett, S., Thomas, C., Williams, G., Gatrell, A., \& Bostock, L. (2003). Beyond 'beer, fags, egg and chips'? Exploring lay understandings of inequalities in health. Sociology of Health \& Illness, 25, 1-23.

Sawyer, R. K. (2001). Emergence in sociology: Contemporary philosophy of mind and some implications for sociological theory, American Journal of Sociology, 107, 551-585.

Smart, C., \& May, V. (2004). Why can't they agree? The underlying complexity of contact and residence disputes. Journal of Social Welfare and Family Law, 26, 347-360.

Smart, C., May, V., Wade, A., \& Furniss, C. (2003). Residence and contact disputes in court (Vol. 1) (Research Series No. 6/03). London: Department for Constitutional Affairs.

Smart, C., May, V., Wade, A., \& Furniss, C. (2005). Residence and contact disputes in court (Vol. 2) (Research Series 4/05). London: Department for Constitutional Affairs. 
Copyright of International Journal of Social Research Methodology is the property of Routledge and its content may not be copied or emailed to multiple sites or posted to a listserv without the copyright holder's express written permission. However, users may print, download, or email articles for individual use. 